\title{
An economic model of long-term use of celecoxib in patients with osteoarthritis
}

\author{
Michael Loyd ${ }^{1}$, Dale Rublee*2 and Philip Jacobs ${ }^{3}$
}

Address: ${ }^{1}$ Michael Loyd \& Associates Ltd, Winnipeg, Manitoba, Canada, ${ }^{2}$ Global Outcomes Research, Pfizer Inc, New York, USA and ${ }^{3}$ University of Alberta, Edmonton, Alberta, Canada

Email: Michael Loyd - mloydassoc@shaw.ca; Dale Rublee* - dale.rublee@pfizer.com; Philip Jacobs - pjacobs@ihe.ca

* Corresponding author

Published: 4 July 2007

BMC Gastroenterology 2007, 7:25 doi:10.1 I86/147|-230X-7-25

This article is available from: http://www.biomedcentral.com/147I-230X/7/25

(c) 2007 Loyd et al; licensee BioMed Central Ltd.

This is an Open Access article distributed under the terms of the Creative Commons Attribution License (http://creativecommons.org/licenses/by/2.0), which permits unrestricted use, distribution, and reproduction in any medium, provided the original work is properly cited.
Received: 8 January 2007

Accepted: 4 July 2007

\begin{abstract}
Background: Previous evaluations of the cost-effectiveness of the cyclooxygenase-2 selective inhibitor celecoxib (Celebrex, Pfizer Inc, USA) have produced conflicting results. The recent controversy over the cardiovascular $(\mathrm{CV})$ risks of rofecoxib and other coxibs has renewed interest in the economic profile of celecoxib, the only coxib now available in the United States. The objective of our study was to evaluate the long-term cost-effectiveness of celecoxib compared with nonselective nonsteroidal anti-inflammatory drugs (nsNSAIDs) in a population of 60-year-old osteoarthritis (OA) patients with average risks of upper gastrointestinal (UGI) complications who require chronic daily NSAID therapy.
\end{abstract}

Methods: We used decision analysis based on data from the literature to evaluate costeffectiveness from a modified societal perspective over patients' lifetimes, with outcomes expressed as incremental costs per quality-adjusted life-year (QALY) gained. Sensitivity tests were performed to evaluate the impacts of advancing age, $\mathrm{CV}$ thromboembolic event risk, different analytic horizons and alternate treatment strategies after UGI adverse events.

Results: Our main findings were: I) the base model incremental cost-effectiveness ratio (ICER) for celecoxib versus nsNSAIDs was $\$ 31,097$ per QALY; 2) the ICER per QALY was $\$ 19,309$ for a model in which UGI ulcer and ulcer complication event risks increased with advancing age; 3 ) the ICER per QALY was $\$ 17,120$ in sensitivity analyses combining serious CV thromboembolic event (myocardial infarction, stroke, CV death) risks with base model assumptions.

Conclusion: Our model suggests that chronic celecoxib is cost-effective versus nsNSAIDs in a population of 60-year-old OA patients with average risks of UGI events.

\section{Background}

Nonselective nonsteroidal anti-inflammatory drugs ( $\mathrm{nsN}$ SAIDs) are widely used to treat acute and chronic pain, including the symptoms of osteoarthritis (OA). The most clinically important adverse events associated with nsNSAID use, ulcer perforations, obstructions, and bleeds (collectively POBs), can be life-threatening and constitute a major public health problem with a large cost to society [1-3]. Uncomplicated peptic ulcers and dyspepsia are not as important clinically as POBs, but, because they are the most prevalent nsNSAID adverse events, their total impact 
in healthcare costs, activity restrictions, production losses, pain, and discomfort is considerable [4-10].

The cyclooxygenase-2 selective inhibitor celecoxib reduces the risks of nsNSAID-induced gastropathy without compromising clinical efficacy. However, evaluations of the cost-effectiveness of celecoxib have produced conflicting results owing mainly to differences in model structures, populations at risk, probabilities, cost-effectiveness indicators, and relative drug prices across countries.

The objective of our study was to evaluate the cost-effectiveness of the long-term use of celecoxib compared with nsNSAIDs in a population of 60-year-old OA patients with average risks of upper gastrointestinal (UGI) complications who require chronic daily NSAID therapy. We assume that acetaminophen is contraindicated or otherwise inferior to NSAID therapy in these patients. Ours is the only coxib evaluation that uses UGI ulcer probabilities from a population comprised only of OA patients, and accounts for reductions in the prices of celecoxib and over-the-counter (OTC) omeprazole after loss of patent protection. Although there have been other lifetime coxib models, only ours extrapolates probabilities and models health states based on long-term evidence from the literature and evaluates celecoxib independently [11-13]. In sensitivity testing, the distinctive features of our study are its evaluations of a comprehensive indicator of serious cardiovascular (CV) thromboembolic risk, alternate treatment regimens after UGI adverse events, and differences in the lengths of the analytic horizon.

\section{Methods}

Cost-effectiveness analysis is used to compare celecoxib (Celebrex, Pfizer Inc, USA) at $200 \mathrm{mg} / \mathrm{d}$, the recommended OA dose, with a combination of diclofenac at $100 \mathrm{mg} / \mathrm{d}$ and naproxen at $1000 \mathrm{mg} / \mathrm{d}$. The target population is 60-year-old patients with moderate to severe OA requiring chronic daily NSAIDs. The outcomes of the model are incremental costs per quality-adjusted life-year (QALY) gained from reductions in symptomatic peptic ulcers, perforations, obstructions, bleeding ulcers (collectively PUBs), and nonulcer dyspepsia. CV thromboembolic events and efficacy in relieving OA symptoms are excluded in the base model on the assumption that there are no differences in these outcomes between celecoxib and nsNSAIDs [14-17].

\section{Model}

The structure of the model used in this study is presented in Figure 1. The problem is structured in Microsoft Excel 2002 as a decision tree with 21 one-year periods. Our literature-based UGI adverse events were comprised of discrete and short-duration NUD, POB and peptic ulcer events in some patients and long-term chronic NUD and
PUD health states in others. The model allowed for multiple $\mathrm{POB}$ and PUB events to recur in time for patients whose short-term discrete events were initially resolved. Patients on nsNSAIDs switch in perpetuity to celecoxib and patients in both cohorts add chronic daily omeprazole after experiencing nonulcer dyspepsia-like symptoms or a PUB event [12]. This assumption recognizes the heightened UGI risks after PUB events, which compound older patients' already high cumulative risks with longterm nsNSAID therapy, the risk that nonulcer dyspepsia might progress to a peptic ulcer, and the potential benefits from symptom relief $[1,18,19]$. In sensitivity analysis, we include 4 alternate post-event treatment approaches also used in clinical practice.

A lifetime analytic horizon is used because many OA sufferers are long-term NSAID users, with high cumulative risks of gastropathy, and some adverse events in the model affect health states for extended periods [20]. Our societal perspective, modified to exclude indirect costs, does not differentiate between patient and insurer costs and is compatible with our use of a lifetime horizon.

We assume that all members of the celecoxib and nsNSAID treatment groups are aged 60 years at the outset and all die in the base model at age 81 years, except those with an adverse gastrointestinal (GI) event resulting in premature death before the end of the 21-year lifetime horizon [12].

We conducted literature searches to obtain representative clinical adverse event rates and information on the longterm courses of health states after adverse events. We

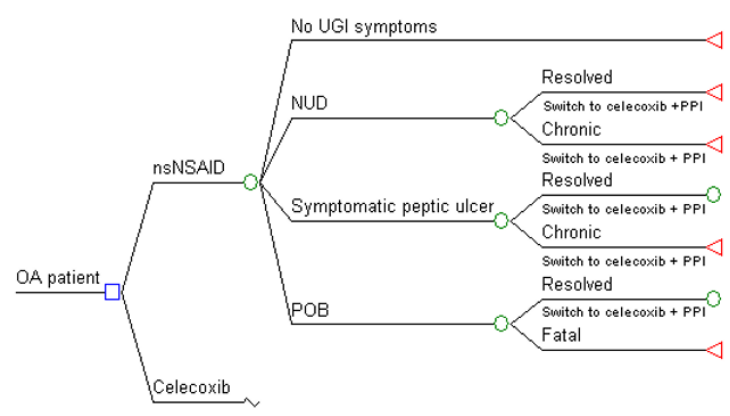

\section{Figure I}

Schematic representation of the study model. nsNSAID, nonselective nonsteroidal anti-inflammatory drug; NUD, nonulcer dyspepsia-like composite; OA, osteoarthritis; PPI, proton pump inhibitor; POB, perforation, obstruction, bleeding ulcer; UGI, upper gastrointestinal. 
sought UGI adverse event rates for patients using the doses of celecoxib and nsNSAIDs recommended for OA patients. Celecoxib is more commonly used for the treatment of the symptoms of OA rather than rheumatoid arthritis. Our search strategies are outlined in more detail in Appendix I.

\section{Probabilities}

Our probabilities for POBs and peptic ulcers are based on event rates in the Successive Celecoxib Efficacy and Safety Study-1 (SUCCESS), the only celecoxib clinical trial that was conducted in a population of OA patients and that used POBs and PUBs as end points [16]. This 12-week trial with a total of 13,274 patients allowed the use of concomitant aspirin (7.1\% baseline prevalence) but excluded high-risk patients with active or recent GI disease, histories of multiple peptic ulcers, various other comorbidities, and those requiring corticosteroids or chronic gastroprotective agents. Patients with a previous history of ulcers comprised $4.1 \%$ of the SUCCESS population, about half the proportions in 2 other major coxib clinical trials, the Celecoxib Long-Term Arthritis Safety Study (CLASS) [21] and the Vioxx Gastrointestinal Outcomes Research study (VIGOR) [22].

The model's POB probabilities per 100 patient-years are 0.8 for nsNSAIDs and 0.1 for celecoxib, representing a crude relative risk reduction (RRR) for celecoxib of 0.875 [16]. This RRR is consistent with those from a pooled analysis of 14 arthritis clinical trials and a 42-week retrospective cohort study of hospitalized POBs [23,24]. Our symptomatic ulcer probabilities per 100 patient-years adapted from SUCCESS are 1.2 for nsNSAIDs and 0.9 for celecoxib $(\mathrm{RRR}=0.25)$.

The base model extrapolates these probabilities over 21 years to calculate $\mathrm{POB}$ cumulative incidence rates of $15.5 \%$ for the naproxen-diclofenac combination and $2.1 \%$ for celecoxib, and respective peptic ulcer rates of $22.4 \%$ and $17.3 \%$ (Table 1) [24-29]. Our assumption that risks are constant over time, which is intended to produce a conservative base-case incremental cost-effectiveness ratio (ICER) for celecoxib, is relaxed in sensitivity testing to allow, more realistically, for increased risk with advancing age. Patients who experience a PUB event in the model are assumed to be 2.7 times more likely than others to suffer a future peptic ulcer or POB [18,25,28,30,31].

The nonulcer GI adverse events of NSAIDs, consisting of dyspepsia (upper abdominal pain or discomfort), nausea, diarrhea, heartburn, constipation, and flatulence, are relevant to economic evaluations because they diminish patients' quality of life and result in increased treatment costs. However, we model only for dyspepsia-like symptoms (including nausea), mainly due to data limitations.
Our clinical probabilities for dyspepsia-like symptoms of $12.0 \%$ (95\% confidence interval [CI], 9.9\%-14.0\%) for an nsNSAID and $7.8 \%(95 \% \mathrm{CI}, 6.0 \%-9.5 \%)$ for celecoxib $200 \mathrm{mg} / \mathrm{d}$ are based on moderate to severe dyspepsia, abdominal pain, or nausea event rates in a pooled analysis of trials in arthritis patients (Table 1) [32]. We adopt these probabilities for our lifetime horizon based on findings that cumulative incidence curves for dyspepsia begin to plateau in trials, may be essentially flat beyond a year, and are unaffected by aging [32-34]. A second pooled analysis comparing OA patients taking celecoxib $200 \mathrm{mg} / \mathrm{d}$ or an nsNSAID found near-identical relative risks (RR) for a similar composite dyspepsia-like end point [35].

\section{QALYs, utilities, and durations of health states}

We assume a base utility value of 0.67 for OA patients without UGI problems and apply utility adjustments for adverse events as deductions from the base (Table 2) [36,37]. The base utility value of 0.67 reflects the fact that the average health of older OA patients, who have a high prevalence of comorbid conditions, is considerably below perfect health, which carries a utility value of 1.0. The annual adjustments for adverse events are the product of the loss of utility from the adverse event and the length of the associated health state expressed as a fraction of a year.

Our disutilities of 0.13 for dyspepsia and peptic ulcers are based on individuals with moderate to severe dyspepsia aged 59 years or more [38]. We corroborated this peptic ulcer disutility by comparing differences in average Health Utility Index values for older OA patients with and without ulcers in a large Canadian database [39]. Disutilities for hospitalized cases were adapted from the literature, with the lengths of inpatient POB and peptic ulcer health states set at averages for such cases in a Maryland hospital database [40,41]. We factored in additional disutilities for $35 \%$ of POB patients with assumed prior symptoms of dyspepsia [42-45].

NSAID-associated nonulcer dyspepsia consists of single events, series of periodic events, or essentially continuous symptoms. Our modeling assumption is that $55 \%$ of dyspepsia patients experience chronic daily symptoms, whereas the remaining patients experience a single 35-day episode of symptoms [12,46-54]. The long-term proportion assumed to be chronic is consistent with the findings of 2 systematic reviews and other long-term studies $[33,52,55,56]$.

The long-term course of peptic ulcer disease is complex, with high rates of peptic ulcer and ulcer-symptom recurrence and chronicity $[4,12,46,54,57-59]$. Our simplified modeling assumption is that the combined point prevalence of patients with active symptomatic ulcers and pos- 
Table I: Clinical probabilities

\begin{tabular}{lll}
\hline Clinical probabilities & Base case (range) & Reference \\
\hline Dyspepsia composite & & {$[32]$} \\
nsNSAIDs & $12.0 \%(9.9 \%-14.0 \%)$ & {$[32]$} \\
Celecoxib & $7.8 \%(6.0 \%-9.5 \%)$ & {$[16,24-29]$} \\
POB 2I-year cumulative incidence & $15.5 \%(4.1 \%-24.8 \%)$ & {$[16,24-29]$} \\
nsNSAIDs & $2.1 \%(0.0 \%-6.1 \%)$ & \\
Celecoxib & & \\
Symptomatic peptic ulcer 2 I-year cumulative incidence & $22.4 \%(10.0 \%-33.7 \%)$ \\
nsNSAIDs & $17.3 \%(10.0 \%-24.0 \%)$ & {$[16,24-29]$} \\
Celecoxib & & \\
PUB 2I-year cumulative incidence & $34.6 \%(19.0 \%-47.3 \%)$ & {$[16,24-29]$} \\
nsNSAIDs & $19.0 \%(10.0 \%-27.2 \%)$ & {$[16,24-29]$} \\
Celecoxib & $4.3 \%(2.5 \%-6.1 \%)$ & {$[18,25,27,28,71,72]$} \\
Age-related increase in PUB risk per year & $2.7(1.5-4.7)$ & {$[18,25,28,30,31]$} \\
PUB risk multiplier for prior PUB event & $90 \%(80 \%-100 \%)$ & {$[145-150]$} \\
Hospitalization rate for POBs & $8.0 \%(5.0 \%-14.0 \%)$ & {$[151-159]$} \\
Mortality rate as percent of POBs & $35 \%(20 \%-50 \%)$ & {$[42,44,45]$} \\
POB with prior dyspepsia & $50 \%(0 \%-65 \%)$ & $5 e e$ text \\
Ratio active ulcers and symptoms to lifetime-prevalent peptic ulcers & $55 \%(0 \%-75 \%)$ & {$[12,33,52,55,56]$} \\
Ratio chronic to lifetime-prevalent nonulcer dyspepsia & \\
\hline
\end{tabular}

nsNSAID, non-selective non-steroidal anti-inflammatory drugs; PUB, symptomatic peptic ulcers, perforations, obstructions, bleeding ulcers; POB, perforation, obstruction, bleeding ulcer; PPI, proton pump inhibitor.

tulcer symptoms is $50 \%$ of lifetime prevalent ulcers developed over the analytic horizon of the model [60]. This means that the cumulative incidence rate in our model would average $6.1 \%$ over the analytic horizon in patients in the nsNSAID treatment arm compared with $4.7 \%$ in those in the celecoxib treatment arm.

To test this assumption, we analyzed the prevalence of ulcers among OA patients over the age of 59 years as determined by a Canadian population-based survey [39]. Seven percent of such patients reported having a current physician-diagnosed ulcer of at least 6 months' duration. This means that the steady state prevalence in a population of OA patients in the community, who are not necessarily NSAID users, exceeds the average prevalence for NSAID users in our base model.

\section{Costs and other data}

We assume that generic celecoxib will be available in 2013, the year of patent expiry, and that the price will be $55 \%$ lower than that of Celebrex, with a range of $30 \%$ to $80 \%$ for sensitivity testing (Table 3) [61-64]. We employ only the estimated generic price in our model after mid 2013. This is consistent with our approach of using prices of generic nsNSAIDs and OTC omeprazole in the model.

Average inpatient hospital costs, lengths of stay, and various hospital statistics were derived from a Maryland inpatient database [40]. We employed principal diagnosis codes and diagnosis-related groups to identify relevant cases and restricted our analyses to patients aged 60 years or more. In the Maryland system, each hospital's charges are based on standardized overhead allocation methods, regulated to reflect the costs (including capital) of services provided, and charge rates apply to all payers without discrimination or discounting. The average cost per adjusted admission in Maryland approximates the national average.

\section{Results}

Incremental treatment costs and benefits of $\$ 4,055$ and 0.1304 QALYs resulted in a base-case celecoxib versus nsNSAID ICER of $\$ 31,097$ per QALY, which falls within the range normally considered to be cost-effective (Table 4 ). The 21-year treatment costs for average patients in the celecoxib and nsNSAID initial treatment groups were $\$ 14,151$ and $\$ 10,096$, respectively, whereas the corresponding QALYs were 10.2982 and 10.1678 .

\section{Sensitivity testing}

Uncertainty

One-way sensitivity analysis results for clinical and economic variables showed that the ICER rose above $\$ 60,000$ per QALY (our standard for cost effectiveness) for only 2 of the variables when ranged over the values in Tables 1 , 2 , or 3, the nsNSAID peptic ulcer and POB probabilities [65]. Other relatively influential variables in 1-way analyses were (in descending order of influence): the celecoxib price, and the event probabilities for a celecoxib peptic ulcer, nsNSAID dyspepsia, and a celecoxib POB. 
Table 2: Utilities and QALY losses for simple health states

\begin{tabular}{lll}
\hline Simple health states & QALY losses & Reference \\
\hline $\begin{array}{l}\text { Dyspepsia (-0.13) } \\
\text { Resolved events (35 days) }\end{array}$ & $-0.01247(-0.005753$ to -0.01496$)$ & {$[38]$} \\
$\begin{array}{l}\text { Chronic per year } \\
\text { Symptomatic peptic ulcers (-0.13) }\end{array}$ & $-0.13(-0.06$ to -0.156$)$ & {$[38]$} \\
Resolved events (35 days) & $-0.01247(-0.005753$ to -0.01496$)$ & {$[38]$} \\
Chronic per year & $-0.13(-0.06$ to -0.156$)$ & {$[38]$} \\
Hospitalization stays & $-0.007926(-0.00634$ to $-0.0095 I 1)$ & {$[12,40,41]$} \\
POB (ALOS = 5.56 days) & $-0.005868(-0.004694$ to -0.007042$)$ & {$[12,40,41]$} \\
Peptic ulcers (ALOS 4.10 days) & $-0.001397(-0.001118$ to -0.001676$)$ & {$[41]$} \\
Outpatient POB ER visit & $-0.00119(-000952$ to -0.001428$)$ & {$[4 I]$} \\
Endoscopy (-0.4325) & $-0.67(-0.536$ to -0.804$)$ & {$[36,37]$} \\
Premature POB death per year &
\end{tabular}

QALY, quality-adjusted life year; POB, perforation, obstruction, bleeding ulcer; ALOS, average length of stay; ER, emergency room. QALY benefits discounted $3 \%$ annually.

Univariate analysis of the sensitivity of the ICER to proportional changes in economic and clinical variables identified the following important variables listed in declining order of their impact on the ICER, along with their threshold values and the proportional changes in each required to attain threshold: celecoxib cost per pill, $\$ 3.72(+41 \%)$ and 21-year probabilities of nsNSAID dyspepsia, $0.0743(-38 \%)$; nsNSAID peptic ulcer, 0.126 ($44 \%)$; nsNSAID POB, 0.061 (-61\%); and celecoxib dyspepsia, $0.1295(+66 \%)$. Hence, the results are robust for all but very large proportional changes.

In addition to the above sensitivity analysis for uncertainty, we assessed variants of the base model in which: 1) risks of PUBs increase with age; 2) the length of the analytic horizon is varied; 3) treatment regimens are altered after adverse events; and 4) different serious CV thromboembolic risks are assumed.

\section{Risks with aging}

Advanced age is a well-documented risk factor for PUBs $[1,3,31,66-70]$. In this sensitivity analysis, we assumed that PUB risks increase by $4.3 \%$ per year after age 60 years $[18,25,27,28,71,72]$. The assumption implies that PUB risks at age 81 years are 2.3 times those at baseline for patients aged 60 years.

The ICER declined to $\$ 19,309$ when age-related increases in PUB risks were factored into the base-model assumptions (Table 5). The cumulative incidence rates were $28.3 \%$ for PUBs in the celecoxib initial treatment group and $48.9 \%$ in nsNSAID group, with corresponding POB cumulative incidence rates of $3.3 \%$ and $23.4 \%$, respectively. When dyspepsia was included, about $60.9 \%$ of nsNSAID patients had at least 1 UGI adverse event over the analytic horizon compared with $36.1 \%$ of celecoxib patients.

\section{Analytic horizon}

The ICER declined $74.9 \%$ from $\$ 124,100$ for a 1 -year model to $\$ 31,097$ for the 21-year model without age risks (Table 5). In the absence of the patent expiration effect, the ICER would have decreased $53.8 \%$ from $\$ 124,100$ to $\$ 57,363$ in a 21-year model. The ICER declined below $\$ 60,000$ per QALY as of year 13 of the analytic horizon in the base case, and year 11 in the sensitivity analysis in which the risk of a PUB event increased with advancing age.

Alternative treatment approaches after a UGI adverse event The base model switched patients initially taking celecoxib or an nsNSAID to regimens of celecoxib plus a proton pump inhibitor (PPI) after dyspepsia or a PUB, an approach that is clinically reasonable given the elevated risks of PUBs and perhaps death after such events. In sensitivity analysis, we also assessed 4 alternate secondary strategies to determine whether the ICER for celecoxib versus an nsNSAID would remain below $\$ 60,000$ per QALY for other possible postevent treatment regimens.

The 4 alternate treatment strategies were: 1) all patients continue on their original treatment regimen, after undergoing temporary courses of PPI healing therapy for PUBs and Helicobacter pylori eradication therapy, as necessary; 2) all patients continue on celecoxib or their nsNSAID and commence PPI cotherapy for the rest of their lives after PUBs; 3) all nsNSAID patients switch to celecoxib plus PPI and celecoxib patients add a PPI for the rest of their lives post-PUB, but nonulcer dyspepsia patients continue on their original treatment regime; and 4) all nsNSAID patients add a PPI after PUBs with all other treatments unchanged after events.

Celecoxib is cost-effective at the sub- $\$ 60,000$ per QALY level for models incorporating each of the 4 post event treatment regimens (Table 5) [37,50,73-77]. Clinical 
Table 3: Cost* and other data summarized

\begin{tabular}{|c|c|c|}
\hline & Base case (range) & Reference \\
\hline Celecoxib 200 mg/d & $\$ 2.64(\$ 2.11-\$ 3.17)$ & http://drugstore.com \\
\hline Naproxen 1000 mg/d & $\$ 0.45(\$ 0.36-\$ 0.54)$ & http://drugstore.com \\
\hline Diclofenac $100 \mathrm{mg} / \mathrm{d}$ & $\$ 0.64(\$ 0.51-\$ 0.77)$ & http://drugstore.com \\
\hline Omeprazole (over-the-counter) $20 \mathrm{mg} / \mathrm{d}$ & $\$ 0.60(\$ 0.48-\$ 0.72)$ & http://drugstore.com \\
\hline Price reduction generic celecoxib & $55 \%(30 \%-80 \%)$ & {$[61,63]$} \\
\hline POB inpatient-hospital plus physician (ALOS = 5.56 days) & $\$ 12,796(\$ 10,234-\$ 15,355)$ & {$[12,40]$} \\
\hline POB outpatient-hospital plus physician & $\$ 1,813(\$ 1,450-\$ 2,176)$ & {$[12,160,161]$} \\
\hline Peptic ulcer inpatient-hospital plus physician (ALOS $=4.10$ days) & $\$ 7,353(\$ 5,882-\$ 8,824)$ & {$[12,40]$} \\
\hline Peptic ulcer outpatient discrete event including endoscopy & $\$ 1,554(\$ 1,243-\$ 1,865)$ & {$[12,160,161]$} \\
\hline Dyspepsia outpatient initial event including endoscopy & $\$ 1,208(\$ 966-\$ 1,450)$ & {$[12,160,161]$} \\
\hline Ongoing annual medical and laboratory costs chronic peptic ulcer or dyspepsia & $\$ 130(\$ 104-\$ 156)$ & [160], Estimates RBRVS \\
\hline POB proportion of surgery DRGs & $14.2 \%$ & {$[40]$} \\
\hline POB admissions through emergency & $89.7 \%$ & {$[40]$} \\
\hline Proportion of peptic ulcer patients admitted to hospital & $4.37 \%$ & {$[40]$} \\
\hline Discount rate for costs and QALYs & $3.0 \%$ & \\
\hline Price inflation rate & $2.0 \%$ & \\
\hline
\end{tabular}

POB, perforation, obstruction, bleeding ulcer; ALOS, average length of stay; RBRVS, resource-based relative value scale; DRGs, diagnosis-related groups. *Drug prices as of February 2006.

probabilities were not sufficiently robust to support a full comparison of ICERs between the alternate regimes.

\section{Depletion of susceptibles}

We also tested an alternate assumption that our SUCCESS POB probabilities were too high for constant-risk extrapolation in our model owing to depletion of susceptibles, the theory that risks are higher in the first few months of NSAID use. The ICER in the base case rose to $\$ 40,841$ per QALY in a base case model with a $30 \%$ reduction in POB risks. The ICER further rose to $\$ 45,955$ per QALY when we extended the $30 \%$ reduction to peptic ulcer probabilities and POBs.

Risks of serious CV thromboembolic events

Our serious CV thromboembolic event (myocardial infarction $[\mathrm{MI}]$ ), stroke, $\mathrm{CV}$ death) costs, and disutilities take into account the impact of the initial event and of subsequent effects, as described in more detail in Appendix II.

Our probabilities of such events are based on a meta-analysis of serious CV thromboembolic risk that found event rates of 1.01 per 100 patient-years in celecoxib patients

Table 4: Base model ICER

\begin{tabular}{llll}
\hline & QALYs & Costs & ICER \\
\hline nsNSAID & 10.1678 & $\$ 10,096$ & \\
Celecoxib & 10.2982 & $\$ 14,151$ & \\
Net incremental & 0.1304 & $\$ 4,055$ & $\$ 31,097$
\end{tabular}

ICER, incremental cost-effective ratio; QALY, quality-adjusted life year; nsNSAID, nonselective nonsteroidal anti-inflammatory drugs. and 1.23 per 100 patient-years in nsNSAID users, with a RR of 0.86 (95\% CI, 0.59-1.26) [15]. The ICER in our model declines to $\$ 17,120$ per QALY when these risks are included, and our results were robust when the RR was varied over all but the extreme upper end of the 95\% CI.

\section{Discussion}

We conducted a cost-effectiveness analysis of long-term celecoxib use compared with nsNSAID use in OA patients. Some of our key assumptions, not adequately addressed in previous models, include a more realistic analytic horizon for UGI adverse events in OA patients with extrapolation and health states based on long-term evidence from the literature, prescription drug prices influenced by termination of patent protection, and ulcer probabilities derived from an OA population.

Our base-case celecoxib ICER of \$31,097 per QALY suggests cost-effectiveness for 60 -year-old OA patients with average baseline UGI risks, $7.1 \%$ of whom were taking aspirin for cardioprophylaxis. The ICER declines to $\$ 19,309$ when account is taken of the increase in PUB risks with advancing age. The ICER, including risks of serious CV thromboembolic events, is $\$ 17,120$ for a model without age-related risks, and ICERs ranged from $\$ 38,807$ to $\$ 46,192$ per QALY in sensitivity analysis with alternate post adverse event treatment strategies.

Our model suggests that the use of short analytic horizons to evaluate long-term celecoxib therapy in OA patients results in biased findings $[20,78,79]$. The diverging cumulative incidence of PUBs in patients in our model's 2 initial treatment groups results in progressively larger 
Table 5: Summary of base model and special sensitivity analysis results

\begin{tabular}{lll}
\hline Model features & No age risks & Sensitivity analyses with age risks \\
\hline Lifetime models & & \\
Base model & $\$ 31,097$ & $\$ 19,309$ \\
Alternative treatments after UGI events models & $\$ 38,807-\$ 46,192$ & $\$ 26,201-\$ 31,777$ \\
CV thromboembolic risks III] & $\$ 17,120$ & $\$ 7,923$ \\
Other analytic horizons & & \\
I year & $\$ 124,100$ & $\$ 124,100$ \\
5 years & $\$ 108,549$ & $\$ 104,104$ \\
8 years & $\$ 93,420$ & $\$ 85,534$ \\
II years & $\$ 67,812$ & $\$ 58,459$ \\
12 years & $\$ 61,191$ & $\$ 51,521$ \\
\hline
\end{tabular}

UGI, upper gastrointestinal; CV, cardiovascular.

differences between comparators' incidences of subsequent PUB events, their ongoing disutilities from chronic peptic ulcers, and their continuing expenses from highercost post-PUB treatment regimens. Additionally, truncated horizons neither capture the full QALY impact of the higher mortality rates in nsNSAID patients nor take into account future celecoxib patent expiration and the related price decreases. Finally, if the risk of PUBs increases with advancing age, as the evidence suggests, the impact of this factor would be muted by short analytic horizons.

Previous coxib evaluations do not appear to have accounted for the patent expiration of celecoxib in 2013 or that of omeprazole in 2002, although PPIs are important drivers of costs in some models and the current OTC price represents a reduction of more than $75 \%$ in the United States.

Our main results are based on regimens of daily nsNSAIDs, whereas intermittent therapy provides adequate relief of OA symptoms for some users of chronic nsNSAIDs in the community. Additionally, some candidates for continuous nsNSAID therapy may interrupt treatment periodically as a strategy to lower MI and stroke risks, even though they suffer disutilities from symptom relief foregone during washout periods. Published coxib evaluations have assumed continuous nsNSAID use because evidence-based probabilities for intermittent treatment regimens are unavailable and myriad patterns of intermittent use are possible [80].

We assessed frequent but intermittent nsNSAID use, which we defined as a minimum of 104 days of therapy per year or approximately 2 days per week for 52 weeks. Our celecoxib versus nsNSAID ICERs were $\$ 43,000$ per QALY or lower depending on the assumed behavior of UGI risks during intermittent use, number of therapy days, and other factors. Hence, our model's results are not contingent on a restrictive assumption of continuous use.
Six evaluations from Europe, Asia, and Canada suggest a favorable economic profile for celecoxib [13,81-85]. However, 5 of these studies with a similar evaluation framework incorporate nsNSAID ulcer probabilities considerably higher than those in the major trials, and international differences in drug prices and health system costs also limit the scope for generalizing these findings to other countries $[16,21,22]$. Two American studies suggest that celecoxib may be cost-effective compared with an nsNSAID $[86,87]$.

Conversely, an influential American study evaluating a celecoxib-rofecoxib hybrid and a Canadian study comparing celecoxib with ibuprofen and diclofenac produced base-case ICERs far outside ranges considered to be costeffective, although both found that coxibs might be costeffective in high-risk populations [12,37]. These 2 studies of $\mathrm{OA}$ and rheumatoid arthritis patients not taking lowdose aspirin relied on controversial longer-term follow-up findings from the CLASS trial for critical assumptions [8895]. These assumptions from CLASS, the earliest celecoxib trial with both POBs and PUBs as end points, conflict with current evidence, including findings from subsequent coxib trials.

Differences in assumptions and model parameters created most of the inconsistencies between the results of the American study by Spiegel and coauthors and our findings. Our model used the SUCCESS trial results as the basis for the key celecoxib and nsNSAID ulcer probabilities, whereas Spiegel used those for a coxib hybrid with predominant weightings from rofecoxib trials and CLASS, with its supratherapeutic doses of celecoxib. More important, Spiegel's results were driven by an assumption that the annual new patient incidence of PUBs would decrease by $35 \%$ per year over its entire 21-year analytic horizon. This pivotal assumption was based on a special-case comparison of the POB incidence rates of nsNSAID patients in the first 6 months and the remaining observational period 
of the CLASS trial [12]. Under the assumed decay function, the cumulative incidence rate of PUBs in nsNSAID patients was $2.6 \%$ in the first year and totaled only $7.2 \%$ in the 21-year horizon of the Spiegel model. In contrast, the 21 -year incidence rate of $34.6 \%$ in our base model was almost triple the upper end of the range in Spiegel's sensitivity test. The differences in the ulcer probabilities are the most important difference between the Spiegel model and the model reported here. Other limitations of the Spiegel model are that it did not take into account any of the following: increases in UGI risks from the aging of its cohorts over the 21-year analytic horizon, increased UGI risks after PUB events, and the price reductions from the expiries of patents on celecoxib and omeprazole.

The data in our review of coxib and nsNSAID trials ranging in duration from 1 to 3 years support the generalization that PUB and POB risks are constant in long clinical trials $[22,30,31,96,97]$. Hence, we believe that the weight of previous and newer trial evidence supports the conclusion of the CLASS authors and others that the POB and PUB event rates observed in nsNSAID patients in the longer follow-up portion of CLASS are biased and that the decline in $\mathrm{POB}$ rates in this trial was aberrant $[66,88,93,94,98]$. The long-term decay function in the Spiegel model also conflicts with evidence from observational studies ranging in length from 2 to 15 years [2529,99-102].

The use of ulcer event rates from the longer-term CLASS trial is 1 reason for the inconsistency of Maetzel and colleagues' Canadian model with our results $[37,80]$. The RRRs in PUB rates range from $47 \%$ to $50 \%$ for coxibs versus nsNSAIDs in typical trials $[16,22,96,97]$. However, for celecoxib compared with diclofenac and ibuprofen, Maetzel's PUB RRs from the CLASS trial were 0.975 and 0.362 , respectively (versus our 0.50 compared with nsNSAIDs) and his POB RRs were 0.917 and 0.386 , respectively (versus our 0.125 compared to nsNSAIDs) [37,80]. Additionally, Maetzel assumed relative dyspepsia risks of 1.00 (versus our 0.65) and relative MI risks of 1.39 to 1.44 (versus our equality of serious CV thromboembolic event risks). Other important differences between the Maetzel model and ours are its 5-year horizon and absence of patent expiration effects, lower probabilities of death from initial compared with repeat POBs, and withdrawal of $95 \%$ of POB patients from further NSAID treatment $[37,80]$.

Probabilities obtained from the SUCCESS trial and our modeling decisions tend to be conservative. Relevant decisions include the assumed independence of PUB risks and age in the base model and the exclusion of indirect costs. The doses used in the SUCCESS trial tended to favor nsNSAIDs: one half the celecoxib patients received double the dose recommended for OA patients, whereas the 100-mg daily diclofenac dose was less than the maximum dose approved for OA patients in participating countries $[16,18,21,23,103]$. Also, diclofenac, the main comparator in the SUCCESS trial, is one of the less toxic nsNSAIDs [104,105].

The results of our model cannot necessarily be generalized to all populations of OA patients. Furthermore, our results are contingent both on the validity of the short-term probabilities in the model and of our approach to extrapolating them over a 21-year period. Although extrapolation is commonly employed in, and generally recommended for, cost-effectiveness analyses of pharmaceuticals, it engenders uncertainties that increase with the length of the period [106].

According to 3 competing theories, CV thromboembolic risks may be associated with individual NSAIDs, coxibs as a class, or all nonaspirin NSAIDs as a class. Incremental cost-effectiveness analysis as employed in this article deals only with differences in risks between nsNSAIDs and celecoxib.

One limitation of the clinical trials in which celecoxib versus nsNSAID CV thromboembolic events have been studied to date, including those in the meta-analysis we used to account for possible differences in CV risks, is that none were originally designed for the primary purpose of assessing differences in these events between treatment groups and they tend to be underpowered for this purpose. Furthermore, the follow-up periods in most of the clinical trials in the meta-analysis that we used were shorter than one year in duration. However, longer observational studies of $\mathrm{CV}$ risk are consistent with a similarity of celecoxib and nsNSAID risks, even though they often employ MI end points, which generally favor nsNSAIDs in clinical trials [107-121]. Current evidence about relative $\mathrm{CV}$ thromboembolic risk is controversial and does not exclude the possibility that celecoxib at OA doses is associated either with elevated or decreased risks of CV thromboembolic events versus nsNSAIDs.

\section{Conclusion}

Our model suggests that the long-term use of celecoxib is cost-effective versus nsNSAIDs in a population of 60 -yearold OA patients with average risks of UGI events.

\section{Competing interests}

This study was supported by Pfizer Inc, New York, USA. Dale Rublee is a full-time employee of Pfizer Inc. He holds stock options in Pfizer. Michael Loyd \& Associates Ltd has consulting agreements with Pfizer Inc for this study and a related study. He owns Pfizer stock. Philip Jacobs received 
honoraria from Pfizer Inc and Michael Loyd \& Associates Ltd.

\section{Authors' contributions}

All authors contributed to the design, conduct and analysis of the study, modeling decisions, and the preparation of the manuscript. All authors read and approved the final manuscript.

\section{Appendix I - literature search strategy}

To obtain clinical probabilities for symptomatic ulcers and POBs, we searched PUBMED for all clinical trials comparing celecoxib versus nsNSAIDs at recommended doses for the treatment of OA patients with symptomatic peptic ulcers or ulcer complications as end points. Key words used in the search were "clinical trial" or "RCT" (randomized clinical trial); "osteoarthritis"; "celecoxib," "ulcer," "hemorrhage," "haemorrhage," "bleed," "bleeding," "perforation," "POB," "PUB", or "PUD" (peptic ulcer disease). We reviewed the resultant abstracts, obtained the full articles as warranted, and reviewed article references. SUCCESS was the only clinical trial with the required end points that exclusively involved OA patients. The SUCCESS trial partially fulfilled our dosage objective, but one half of the celecoxib patients received double the 200-mg daily dose recommended for OA patients.

Articles were identified on 2 other clinical trials with some relevance, but both included OA and rheumatoid arthritis patients and also proved to be inferior matches in other respects $[21,23]$. We excluded the CLASS study from all PUB analyses owing to controversies associated with the study's ulcer-related results, and its use of $800 \mathrm{mg} / \mathrm{d}$ celecoxib doses, which are quadruple the dose recommended for OA patients. We compared POB RRs from SUCCESS with those from the second best match, an article on a pooled study of randomized clinical trials. However, this article did not report event rates for symptomatic peptic ulcers or PUBs.

We also searched for observational studies that most closely matched our criteria, given the dearth of relevant celecoxib clinical trial data to compare with SUCCESS probabilities. We wanted insights into adverse event rates in the community, and $\mathrm{POB}$ or PUB rates over longer periods. Two case control studies involving celecoxib were identified, one with average-risk patients and another with high-risk patients $[24,122]$. Only the former was pertinent to the current analysis.

For clinical probabilities of dyspepsia, we sought articles on clinical trials involving OA patients and comparing nsNSAIDs and celecoxib at doses normally used in OA patients, with relatively comprehensive definitions of dyspepsia, including related UGI symptoms, but excluding heartburn as a dominant symptom. Our search used key words "clinical trial" or "RCT," "dyspepsia," "abdominal pain," "UGI discomfort" or "NUD," "celecoxib," "NSAIDs," and "arthritis." We identified 3 articles, but the article based on CLASS was eliminated because supratherapeutic doses of celecoxib were used $[32,34,35]$.

Various other searches were conducted including systematic searches on PubMed for all articles on the risks and courses of dyspepsia, peptic ulcers, POBs, strokes and MIs over extended periods. The objectives were to determine, based on the best available evidence, how to model the period prevalence rates, annual incidence rates, and durations of events over our analytic horizon, which extends far beyond the durations of clinical trials. We searched the literature systematically and manually for multivariate analyses of the risk factors for peptic ulcers and POBs, focusing especially on analyses with age as a continuous variable or with multiple categorical age interval variables. We also systematically reviewed other analyses powered to provide breakdowns of RRs by age.

The searches for UGI events were last conducted in January 2005.

\section{Appendix 2 - costs and disutilities of CV thromboembolic events}

Health sector costs for first MIs or strokes included initial hospitalizations, ongoing maintenance costs, and forecasted excess costs of future care [40,123-130]. Among survivors, QALY decrements consisted of losses from initial hospital stays, ongoing postevent disutilities of 0.05 for MI survivors and 0.25 for stroke survivors, plus loss of life expectancy assuming that mortality rates by age for survivors were double the rates for the general population [37,39,131-141]. The impacts of first-in-model events on patients with a history of MI or stroke at baseline reflected patients' premodel reductions in life expectancy, utilities, and higher health sector costs [142-144]. The risks of CV thromboembolic events were assumed to increase $5 \%$ per year in sensitivity analyses that also assumed age-related increases in the risks of UGI adverse events.

\section{References}

I. Dubois RW, Melmed GY, Henning JM, Bernal M: Risk of upper gastrointestinal injury and events in patients treated with cyclooxygenase (COX)-I/COX-2 nonsteroidal antiinflammatory drugs (NSAIDs), COX-2 selective NSAIDs, and gastroprotective cotherapy. An appraisal of the literature. J Clin Rheumatol 2004, 10:178-189.

2. Smalley WE, Griffin MR, Fought RL, Ray WA: Excess costs from gastrointestinal disease associated with nonsteroidal antiinflammatory drugs. J Gen Intern Med 1996, I I:46 I-469.

3. Wolfe MM, Lichtenstein DR, Singh G: Gastrointestinal toxicity of nonsteroidal antiinflammatory drugs. N Engl J Med I999, 340:1888-1899.

4. Ashton T: Cost-effectiveness of alternative medications in the treatment of duodenal ulcer. Scand J Gastroenterol 1991, 26:82-88. 
5. Griffin MR: Epidemiology of nonsteroidal anti-inflammatory drug-associated gastrointestinal injury. Am J Med 1998, 104:23S-29S.

6. Henke CJ, Levin TR, Henning JM, Potter LP: Work loss costs due to peptic ulcer disease and gastroesophageal reflux disease in a health maintenance organization. Am J Gastroenterol 2000 95:788-792.

7. Logan R, Delaney $B: A B C$ of the upper gastrointestinal tract: implications of dyspepsia for the NHS. BMJ 200I, 323:675-677.

8. Severens JL, Laheij RJ, Jansen JB, Van der Lisdonk EH, Verbeek AL: Estimating the cost of lost productivity in dyspepsia. Aliment Pharmacol Ther 1998, 12:919-923.

9. Sonnenberg A, Everhart JE: Health impact of peptic ulcer in the United States. Am J Gastroenterol 1997, 92:6/4-620.

10. Tibblin G: Introduction to the epidemiology of dyspepsia. Scand J Gastroenterol Suppl 1985, 109:29-33.

II. Bae SC, Corzillius M, Kuntz KM, Liang MH: Cost-effectiveness of low dose corticosteroids versus non-steroidal anti-inflammatory drugs and COX-2 specific inhibitors in the long-term treatment of rheumatoid arthritis. Rheumatology (Oxford) 2003, 42:46-53.

12. Spiegel BM, Targownik L, Dulai GS, Gralnek IM: The cost-effectiveness of cyclooxygenase-2 selective inhibitors in the management of chronic arthritis. Ann Intern Med 2003, I 38:795-806.

13. Yun HR, Bae SC: Cost-effectiveness analysis of NSAIDs, NSAIDs with concomitant therapy to prevent gastrointestinal toxicity, and COX-2 specific inhibitors in the treatment of rheumatoid arthritis. Rheumatol Int 2005, 25:9-14.

14. Deeks JJ, Smith LA, Bradley MD: Efficacy, tolerability, and upper gastrointestinal safety of celecoxib for treatment of osteoarthritis and rheumatoid arthritis: systematic review of randomised controlled trials. BMJ 2002, 325:619-626.

15. Simon LS, White W, MacDonald T, Pan S, Rosenstein R, Gaffney M: Cardiovascular safety of celecoxib: a meta-analysis of $4 \mathrm{I}$ clinical studies in 44,300 patients [abstract]. Presented at the American College of Rheumatology Annual Meeting, November 12 17, 2005; San Diego, CA; 2005

16. Singh G, Fort JG, Goldstein JL, Levy RA, Hanrahan PS, Bello AE, Andrade-Ortega L, Wallemark C, Agrawal NA, Eisen GM, Stenson WF, Triadafilopoulos G, Investigators SUCCESSI: Celecoxib versus naproxen and diclofenac in osteoarthritis patients: SUCCESS-I Study [published correction appears in: Am J Med. 2006; I I 9:80 I]. Am J Med 2006, I I 9:255-266.

17. White WB, Faich G, Borer JS, Makuch RW: Cardiovascular thrombotic events in arthritis trials of the cyclooxygenase-2 inhibitor celecoxib. Am J Cardiol 2003, 92:4II-4I 8.

18. Hernandez-Diaz S, Rodriguez LA: Association between nonsteroidal anti-inflammatory drugs and upper gastrointestina tract bleeding/perforation: an overview of epidemiologic studies published in the 1990s. Arch Intern Med 2000, 160:2093-2099.

19. Hsu PI, Lai KH, Lo GH, Tseng HH, Lo CC, Chen HC, Tsai WL, Jou HS, Peng NJ, Chien CH, Chen JL, Hsu PN: Risk factors for ulcer development in patients with non-ulcer dyspepsia: a prospective two year follow up study of $\mathbf{2 0 9}$ patients. Gut 2002, 5I:15-20.

20. Canadian Coordinating Office for Health Technology Assessment (CCOHTA). Guidelines for economic evaluation of pharmaceuticals. November 19971997 [https:// www.ccohta.ca/publications/pdf/peg e.pdf].

21. Silverstein FE, Faich G, Goldstein JL, Simon LS, Pincus T, Whelton A Makuch R, Eisen G, Agrawal NM, Stenson WF, Burr AM, Zhao WW, Kent JD, Lefkowith JB, Verburg KM, Geis GS: Gastrointestinal toxicity with celecoxib vs nonsteroidal anti-inflammatory drugs for osteoarthritis and rheumatoid arthritis: the CLASS study: A randomized controlled trial. Celecoxib Long-term Arthritis Safety Study. JAMA 2000, 284:1247-1255.

22. Bombardier C, Laine L, Reicin A, Shapiro D, Burgos-Vargas R, Davis B, Day R, Ferraz MB, Hawkey C), Hochberg MC, Kvien TK, Schnitzer $\mathrm{T}$ : Comparison of upper gastrointestinal toxicity of rofecoxib and naproxen in patients with rheumatoid arthritis. VIGOR Study Group. N Engl J Med 2000, 343:I520-I528, 2 pages following.

23. Goldstein JL, Silverstein FE, Agrawal NM, Hubbard RC, Kaiser J, Maurath C], Verburg KM, Geis GS: Reduced risk of upper gas- trointestinal ulcer complications with celecoxib, a novel COX-2 inhibitor. Am J Gastroenterol 2000, 95: I68I-1690.

24. Mamdani M, Rochon PA, Juurlink DN, Kopp A, Anderson GM, Naglie G, Austin PC, Laupacis A: Observational study of upper gastrointestinal haemorrhage in elderly patients given selective cyclo-oxygenase-2 inhibitors or conventional non-steroidal anti-inflammatory drugs. BM/ 2002, 325:624.

25. Fries JF, Williams CA, Bloch DA, Michel BA: Nonsteroidal antiinflammatory drug-associated gastropathy: incidence and risk factor models. Am J Med I991, 9 1:213-222.

26. Fries JF: The epidemiology of NSAID gastropathy. The ARAMIS experience. I Clin Rheumatol I998, 4:SII-SI6.

27. MacDonald TM, Morant SV, Robinson GC, Shield MJ, McGilchrist MM, Murray FE, McDevitt DG: Association of upper gastrointestinal toxicity of non-steroidal anti-inflammatory drugs with continued exposure: cohort study. BMJ 1997, 31 5:1333-1337.

28. Singh G, Triadafilopoulos G: Epidemiology of NSAID induced gastrointestinal complications. J Rheumatol Suppl 1999, 56:18-24.

29. Wolfe F, Hawley DJ: The comparative risk and predictors of adverse gastrointestinal events in rheumatoid arthritis and osteoarthritis: a prospective 13 year study of 2131 patients. J Rheumatol 2000, 27:1668-1673.

30. Serrano P, Lanas A, Arroyo MT, Ferreira IJ: Risk of upper gastrointestinal bleeding in patients taking low-dose aspirin for the prevention of cardiovascular diseases. Aliment Pharmacol Ther 2002, 16:1945-1953.

31. Silverstein FE, Graham DY, Senior JR, Davies HW, Struthers BJ, Bittman RM, Geis GS: Misoprostol reduces serious gastrointestinal complications in patients with rheumatoid arthritis receiving nonsteroidal anti-inflammatory drugs. A randomized, double-blind, placebo-controlled trial. Ann Intern Med 1995, I 23:24I-249

32. Bensen WG, Zhao SZ, Burke TA, Zabinski RA, Makuch RW, Maurath C], Agrawal NM, Geis GS: Upper gastrointestinal tolerability of celecoxib, a COX-2 specific inhibitor, compared to naproxen and placebo. I Rheumatol 2000, 27:1876-1883.

33. El Serag HB, Talley NJ: Systemic review: the prevalence and clinical course of functional dyspepsia. Aliment Pharmacol Ther 2004, 19:643-654.

34. Goldstein JL, Eisen GM, Burke TA, Pena BM, Lefkowith J, Geis GS: Dyspepsia tolerability from the patients' perspective: a comparison of celecoxib with diclofenac. Aliment Pharmacol Ther 2002, 16:819-827.

35. McKenna F, Arguelles L, Burke T, Lefkowith J, Geis GS: Upper gastrointestinal tolerability of celecoxib compared with diclofenac in the treatment of osteoarthritis and rheumatoid arthritis. Clin Exp Rheumatol 2002, 20:35-43.

36. Kaplan RM, Anderson JP, Wu AW, Mathews WC, Kozin F, Orenstein D: The Quality of Well-being Scale. Applications in AIDS, cystic fibrosis, and arthritis. Med Care 1989, 27:S27-S43.

37. Maetzel A, Krahn M, Naglie G: The cost effectiveness of rofecoxib and celecoxib in patients with osteoarthritis or rheumatoid arthritis. Arthritis Rheum 2003, 49:283-292.

38. Groeneveld PW, Lieu TA, Fendrick AM, Hurley LB, Ackerson LM, Levin TR, Allison JE: Quality of life measurement clarifies the cost-effectiveness of Helicobacter pylori eradication in peptic ulcer disease and uninvestigated dyspepsia. Am J Gastroenterol 200I, 96:338-347.

39. Canadian Institute for Health Information. Canadian Community Health Survey (CCHS): Cycle I.I: extending the wealth of health data in Canada. 20032003 [http://www.stat can.ca/english/concepts/health/cchsinfo.htm].

40. Health Services Cost Review Commission. Maryland Inpatient Public Use File July 2003-June 2004. 2004.

4I. Ebell MH, Warbasse L, Brenner C: Evaluation of the dyspeptic patient: a cost-utility study. I Fam Pract 1997, 44:545-555.

42. Holvoet J, Terriere L, Van Hee W, Verbist L, Fierens E, Hautekeete ML: Relation of upper gastrointestinal bleeding to non-steroidal anti-inflammatory drugs and aspirin: a case-control study. Gut 1991, 32:730-734

43. Rorbaek-Madsen M, Fischer L, Thomsen H, Wara P: Late outcome of bleeding gastric ulcer. Five to eight years' follow-up. Scand J Gastroenterol 1994, 29:983-987.

44. Singh G, Rosen RD: NSAID induced gastrointestinal complications: the ARAMIS perspective--1997. Arthritis, Rheuma- 
tism, and Aging Medical Information System. I Rheumatol Suppl 1998, 5 I:8-16.

45. Zeidler H: Epidemiology and economics of NSAID-induced gastropathy. Scand J Rheumatol Suppl 1992, 92:3-8.

46. North of England Dyspepsia Guideline Development Group. Dyspepsia: managing dyspepsia in adults in primary care. Newcastle upon Tyne (UK): Center for Health Services Research, University of Newcastle. August 20042004 [http:// www.guideline.gov/summaryl

pdf.aspx?doc id $=5634$ \&stat $=\mid$ \&string $=]$

47. Eisen GM, Dominitz JA, Faigel DO, Goldstein JA, Kalloo AN, Petersen BT, Raddawi HM, Ryan ME, Vargo || III, Young HS, Fanelli RD, Hyman $\mathrm{NH}$, Wheeler-Harbaugh J: The role of endoscopy in dyspepsia. Gastrointest Endosc 200I, 54:8I5-8I7.

48. Laheij RJ, Severens JL, Jansen JB, van de Lisdonk EH, Verbeek AL: Management in general practice of patients with persistent dyspepsia. A decision analysis. J Clin Gastroenterol 1997, 25:563-567.

49. Laheij RJ, van Rossum LG, Heinen N, Jansen JB: Long-term followup of empirical treatment or prompt endoscopy for patients with persistent dyspeptic symptoms? Eur J Gastroenterol Hepatol 2004, 16:785-789.

50. Lai KC, Chu KM, Hui WM, Wong BC, Hu WH, Wong WM, Chan AO, Wong J, Lam SK: Celecoxib compared with lansoprazole and naproxen to prevent gastrointestinal ulcer complications. Am J Med 2005, I I 8: | 27|- 1278.

5I. Laine L, Schoenfeld P, Fennerty MB: Therapy for Helicobacter pylori in patients with nonulcer dyspepsia. A meta-analysis of randomized, controlled trials. Ann Intern Med 200I, 134:36|-369.

52. Lindell GH, Celebioglu F, Graffner HO: Non-ulcer dyspepsia in the long-term perspective. Eur J Gastroenterol Hepatol 1995, 7:829-833

53. Meineche-Schmidt V, Talley NJ, Pap A, Kordecki H, Schmid V, Ohlsson $L$, Wahlqvist $P$, Wiklund I, Bolling-Sternevald E: Impact of functional dyspepsia on quality of life and health care consumption after cessation of antisecretory treatment. A multicentre 3-month follow-up study. Scand J Gastroenterol 1999, 34:566-574.

54. Ryder SD, O'Reilly S, Miller RJ, Ross J, Jacyna MR, Levi AJ: Long term acid suppressing treatment in general practice. BMJ 1994, 308:827-830.

55. Heikkinen $M$, Farkkila $M$ : What is the long-term outcome of the different subgroups of functional dyspepsia? Aliment Pharmacol Ther 2003, 18:223-229.

56. Janssen HA, Muris JW, Knottnerus JA: The clinical course and prognostic determinants of non-ulcer dyspepsia: a literature review. Scand J Gastroenterol 1999, 34:546-550.

57. Jensen DM: Economic assessment of peptic ulcer disease treatments. Scand J Gastroenterol Suppl 1988, 1 46:214-224.

58. McCarthy DM: Nonsteroidal antiinflammatory drug-induced ulcers: management by traditional therapies. Gastroenterology 1989, 96:662-674.

59. Petersen H, Kristensen P, Johannessen T, Kleveland PM, Dybdahl JH, Myrvold $\mathrm{H}$ : The natural course of peptic ulcer disease and its predictors. Scand J Gastroenterol 1995, 30:17-24.

60. Everhart JE, Byrd-Holt D, Sonnenberg A: Incidence and risk factors for self-reported peptic ulcer disease in the United States. Am J Epidemiol 1998, 147:529-536.

61. Congressional Budget Office. How increased competition from generic drugs has affected prices and returns in the pharmaceutical industry. July 19981998 [http://www.cbo.gov/ showdoc.cfm?index $=655$ \&sequence $=0$.]

62. Anis $\mathrm{AH}$, Guh DP, Woolcott J: Lowering generic drug prices: less regulation equals more competition. Med Care 2003, 4I:|35-|4|.

63. Frank RG, Seiguer E: Generic drug competition in the US. 2003 [http:www.touchbriefings.cocdpcditem.cfm? NID $=15 \& C I D=5 \& C F I 7 \&$ CFTO KEN=96259395]

64. Grabowski H: Patents, innovation and access to new pharmaceuticals. Duke University. 2002 [http://levine.sscnet.ucla.edu/ archive/grabow-patents innov.pdf].

65. Newhouse JP: US and UK health economics: two disciplines separated by a common language? Health Econ 1998, 7 Suppl I:S79-S92.
66. Bombardier C: An evidence-based evaluation of the gastrointestinal safety of coxibs. Am J Cardiol 2002, 89:3D-9D.

67. Fries JF, Murtagh KN, Bennett M, Zatarain E, Lingala B, Bruce B: The rise and decline of nonsteroidal antiinflammatory drug-associated gastropathy in rheumatoid arthritis. Arthritis Rheum 2004, 50:2433-2440.

68. Hernandez-Diaz S, Rodriguez LA: Incidence of serious upper gastrointestinal bleeding/perforation in the general population: review of epidemiologic studies. I Clin Epidemiol 2002, 55:157-163.

69. Laine L: Gastrointestinal effects of NSAIDs and coxibs. J Pain Symptom Manage 2003, 25:S32-S40.

70. Tannenbaum H, Peloso PM, Russell AS, Marlow B: An evidencebased approach to prescribing NSAIDs in the treatment of osteoarthritis and rheumatoid arthritis: The Second Canadian Consensus Conference. Can J Clin Pharmacol 2000, 7 Suppl A:4A-16A.

7I. Longstreth GF: Epidemiology of hospitalization for acute upper gastrointestinal hemorrhage: a population-based study. Am J Gastroenterol 1995, 90:206-2 I0.

72. Moore RA: Helicobacter pylori and peptic ulcer, a systematic review of effectiveness and an overview of the economic benefits of implementing what is known to be cost effective. 1994 [http://www.jr2.ox.ac.uk/bandolier/bandopubs/hpyl/hpall.html].

73. Chan FK, Hung LC, Suen BY, Wu JC, Lee KC, Leung VK, Hui AJ, To KF, Leung WK, Wong VW, Chung SC, Sung J]: Celecoxib versus diclofenac and omeprazole in reducing the risk of recurrent ulcer bleeding in patients with arthritis. N Engl J Med 2002, 347:2104-2110.

74. Claxton $\mathrm{K}$ : The irrelevance of inference: a decision-making approach to the stochastic evaluation of health care technologies. J Health Econ 1999, 18:34|-364.

75. Hawkey CJ, Langman MJ: Non-steroidal anti-inflammatory drugs: overall risks and management. Complementary roles for COX-2 inhibitors and proton pump inhibitors. Gut 2003, 52:600-608.

76. Hunt RH, Barkun AN, Baron D, Bombardier C, Bursey FR, Marshall JR, Morgan DG, Pare P, Thomson AB, Whittaker JS: Recommendations for the appropriate use of anti-inflammatory drugs in the era of the coxibs: defining the role of gastroprotective agents. Can J Gastroenterol 2002, 16:231-240.

77. Laine L: Proton pump inhibitor co-therapy with nonsteroidal anti-inflammatory drugs--nice or necessary? Rev Gastroenterol Disord 2004, 4 Suppl 4:S33-S4I.

78. Drummond MF, O'Brien B, Stoddart GL, Torrance GW, editors: Methods for the Economic Evaluation of Health Care Programmes New York, Oxford University Press; 1997.

79. Gold MR, Siegel JE, Russell LB, Weinstein MC editors: Cost-effectiveness in Health and Medicine New York, Oxford University Press; 1996.

80. Maetzel A, Krahn M, Naglie G: The cost-effectiveness of celecoxib and rofecoxib in patients with osteoarthritis or rheumatoid arthritis. Canadian Coordinating Office for Health Technology Assessment Technology Report No. 23. 2001

8I. Chancellor JV, Hunsche E, de Cruz E, Sarasin FP: Economic evaluation of celecoxib, a new cyclo-oxygenase 2 specific inhibitor, in Switzerland. Pharmacoeconomics 200I, 19 Suppl I:59-75.

82. Haglund U, Svarvar P: The Swedish ACCES model: predicting the health economic impact of celecoxib in patients with osteoarthritis or rheumatoid arthritis. Rheumatology (Oxford) 2000, 39 Suppl 2:51-56.

83. Svarvar P, Aly A: Use of the ACCES model to predict the health economic impact of celecoxib in patients with osteoarthritis or rheumatoid arthritis in Norway. Rheumatology (Oxford) 2000, 39 Suppl 2:43-50.

84. You JH, Lee KK, Chan TY, Lau WH, Chan FK: Arthritis treatment in Hong Kong--cost analysis of celecoxib versus conventional NSAIDS, with or without gastroprotective agents. Aliment Pharmacol Ther 2002, 16:2089-2096.

85. Zabinski RA, Burke TA, Johnson J, Lavoie F, Fitzsimon C, Tretiak R, Chancellor JV: An economic model for determining the costs and consequences of using various treatment alternatives for the management of arthritis in Canada. Pharmacoeconomics 200I, 19 Suppl I:49-58.

86. El Serag HB, Graham DY, Richardson P, Inadomi JM: Prevention of complicated ulcer disease among chronic users of nonsteroi- 
dal anti-inflammatory drugs: the use of a nomogram in costeffectiveness analysis. Arch Intern Med 2002, 162:2105-21I0.

87. Schaefer M, DeLattre M, Gao X, Stephens J, Botteman M, Morreale A: Assessing the cost-effectiveness of COX-2 specific inhibitors for arthritis in the Veterans Health Administration. Curr Med Res Opin 2005, 21:47-60.

88. Geis GS: Are selective COX 2 inhibitors superior to traditional NSAIDs? Pharmacia's response to editorial. BMJ 2002, 325:161.

89. Gottlieb S: Researchers deny any attempt to mislead the public over JAMA article on arthritis drug. BMJ 200I, 323:30I.

90. Hrachovec JB, Mora M: Reporting of 6-month vs I 2-month data in a clinical trial of celecoxib. JAMA 200I, 286:2398-2400.

91. Juni P, Rutjes AW, Dieppe PA: Are selective COX 2 inhibitors superior to traditional non steroidal anti-inflammatory drugs? $B M]$ 2002, 324: $1287-1288$.

92. Juni P, Sterchi R, Dieppe P: Systematic review of celecoxib for osteoarthritis and rheumatoid arthritis. Problems compromise review's validity. BMJ 2003, 326:334.

93. Scheiman JM: Gastroduodenal safety of cyclooxygenase-2 inhibitors. Curr Pharm Des 2003, 9:21 97-2206.

94. Stover RR: Are selective COX $\mathbf{2}$ inhibitors superior to traditional NSAIDs? Both the CLASS and VIGOR trials support the COX 2 hypothesis. BMJ 2002, 325:161.

95. Ramey DR, Watson DJ, Yu C, Bolognese JA, Curtis SP, Reicin AS: The incidence of upper gastrointestinal adverse events in clinical trials of etoricoxib vs. non-selective NSAIDs: an updated combined analysis. Curr Med Res Opin 2005, 21:7I 5-722

96. Schnitzer TJ, Burmester GR, Mysler E, Hochberg MC, Doherty M, Ehrsam E, Gitton X, Krammer G, Mellein B, Matchaba P, Gimona A Hawkey Cl: Comparison of lumiracoxib with naproxen and ibuprofen in the Therapeutic Arthritis Research and Gastrointestinal Event Trial (TARGET), reduction in ulcer complications: randomised controlled trial. Lancet 2004 , 364:665-674.

97. Hawkey CJ, Farkouh M, Gitton X, Ehrsam E, Huels J, Richardson P: Therapeutic arthritis research and gastrointestinal event trial of lumiracoxib - study design and patient demographics. Aliment Pharmacol Ther 2004, 20:5 I-63.

98. Garcia Rodriguez LA, Hernandez-Diaz S: Risk of uncomplicated peptic ulcer among users of aspirin and nonaspirin nonsteroidal antiinflammatory drugs. Am J Epidemiol 2004, 159:23-3I.

99. Gutthann SP, Garcia Rodriguez LA, Raiford DS: Individual nonsteroidal antiinflammatory drugs and other risk factors for upper gastrointestinal bleeding and perforation. Epidemiology 1997, 8:18-24.

100. Perez-Gutthann S, Garcia-Rodriguez LA, Duque-Oliart A, VarasLorenzo C: Low-dose diclofenac, naproxen, and ibuprofen cohort study. Pharmacotherapy 1999, 19:854-859.

10I. Singh G: Recent considerations in nonsteroidal anti-inflammatory drug gastropathy. Am J Med 1998, I05:3 IS-38S

102. Laine L: Approaches to nonsteroidal anti-inflammatory drug use in the high-risk patient. Gastroenterology 200I, 120:594-606.

103. Henry D, Lim LL, Garcia Rodriguez LA, Perez GS, Carson JL, Griffin M, Savage R, Logan R, Moride Y, Hawkey C, Hill S, Fries JT: Variability in risk of gastrointestinal complications with individual non-steroidal anti-inflammatory drugs: results of a collaborative meta-analysis. $B M]$ 1996, 3 I 2:1563-1566.

104. Langman MJ, Weil J, Wainwright P, Lawson DH, Rawlins MD, Logan RF, Murphy M, Vessey MP, Colin-Jones DG: Risks of bleeding peptic ulcer associated with individual non-steroidal anti-inflammatory drugs. Lancet 1994, 343:1075-1078.

105. Drummond M, McGuire A, editors: Economic Evaluation in Health Care. Merging Theory With Practice London, Oxford University Press; $200 \mathrm{I}$.

106. Andersohn F, Suissa S, Garbe E: Use of first- and second-generation cyclooxygenase-2-selective nonsteroidal antiinflammatory drugs and risk of acute myocardial infarction. Circulation 2006, II 3:1950-1957.

107. Graham DJ, Campen D, Hui R, Spence M, Cheetham C, Levy G, Shoor $S$, Ray WA: Risk of acute myocardial infarction and sudden cardiac death in patients treated with cyclo-oxygenase 2 selective and non-selective non-steroidal anti-inflammatory drugs: nested case-control study. Lancet 2005, 365:475-48I.

108. Hippisley-Cox J, Coupland C: Risk of myocardial infarction in patients taking cyclo-oxygenase- 2 inhibitors or conventional non-steroidal anti-inflammatory drugs: population based nested case-control analysis. BMJ 2005, 330: 1366.

109. Huang WF, Hsiao FY, Tsai YW, Wen YW, Shih YT: Cardiovascular events associated with long-term use of celecoxib, rofecoxib and meloxicam in Taiwan : an observational study. Drug Saf 2006, 29:26I-272.

I I0. Johnsen SP, Larsson H, Tarone RE, McLaughlin JK, Norgard B, Friis S, Sorensen HT: Risk of hospitalization for myocardial infarction among users of rofecoxib, celecoxib, and other NSAIDs: a population-based case-control study. Arch Intern Med 2005 , 165:978-984.

III. Kimmel SE, Berlin JA, Reilly M, Jaskowiak J, Kishel L, Chittams J, Strom BL: Patients exposed to rofecoxib and celecoxib have different odds of nonfatal myocardial infarction. Ann Intern Med 2005, 142:157-164.

I 12. Levesque LE, Brophy JM, Zhang B: The risk for myocardial infarction with cyclooxygenase- 2 inhibitors: a population study of elderly adults. Ann Intern Med 2005, I 42:48I-489.

113. Mamdani M, Rochon P, Juurlink DN, Anderson GM, Kopp A, Naglie G, Austin PC, Laupacis A: Effect of selective cyclooxygenase 2 inhibitors and naproxen on short-term risk of acute myocardial infarction in the elderly. Arch Intern Med 2003, 163:48I-486.

114. Ray WA, Stein CM, Daugherty JR, Hall K, Arbogast PG, Griffin MR: COX-2 selective non-steroidal anti-inflammatory drugs and risk of serious coronary heart disease. Lancet 2002, 360:1071-1073.

II5. Shaya FT, Blume SW, Blanchette CM, Weir MR, Mullins CD: Selective cyclooxygenase- 2 inhibition and cardiovascular effects: an observational study of a Medicaid population. Arch Intern Med 2005, 165:181-186.

116. Singh G, Graham D, Wang H, Mithal A, Triadafilopoulos G: Concomitant aspirin use reduces the risk of acute myocardial infarction in users of cyclooxygenase-2 selective and some nonselective nonsteroidal anti-inflammatory drugs [abstract]. Presented at the European League Against Rheumatism Annual Meeting, June 2I-26, 2006, The Netherlands; 2006.

II7. Solomon DH, Schneeweiss S, Glynn RJ, Kiyota Y, Levin R, Mogun H, Avorn J: Relationship between selective cyclooxygenase-2 inhibitors and acute myocardial infarction in older adults. Circulation 2004, 109:2068-2073.

I 18. Solomon DH, Avorn J, Sturmer T, Glynn RJ, Mogun H, Schneeweiss $\mathrm{S}$ : Cardiovascular outcomes in new users of coxibs and nonsteroidal antiinflammatory drugs: high-risk subgroups and time course of risk. Arthritis Rheum 2006, 54:I378-I389.

119. Velentgas P, West W, Cannuscio CC, Watson DJ, Walker AM: Cardiovascular risk of selective cyclooxygenase-2 inhibitors and other non-aspirin non-steroidal anti-inflammatory medications. Pharmacoepidemiol Drug Saf 2006.

120. McGettigan P, Henry D: Cardiovascular risk and inhibition of cyclooxygenase: a systematic review of the observational studies of selective and nonselective inhibitors of cyclooxygenase 2. JAMA 2006, 296:1633-1644.

12I. Norgard B, Pedersen L, Johnsen SP, Tarone RE, McLaughlin JK, Friis $S$, Sorensen HT: COX-2-selective inhibitors and the risk of upper gastrointestinal bleeding in high-risk patients with previous gastrointestinal diseases: a population-based casecontrol study. Aliment Pharmacol Ther 2004, 19:817-825.

122. Bergman L, van der Meulen JH, Limburg M, Habbema JD: Costs of medical care after first-ever stroke in The Netherlands. Stroke 1995, 26: 1830-1836.

123. Dewey HM, Thrift AG, Mihalopoulos C, Carter R, Macdonell RA, McNeil J], Donnan GA: Cost of stroke in Australia from a societal perspective: results from the North East Melbourne Stroke Incidence Study (NEMESIS). Stroke 200I, 32:2409-24I6.

124. Diringer MN, Edwards DF, Mattson DT, Akins PT, Sheedy CW, Hsu CY, Dromerick AW: Predictors of acute hospital costs for treatment of ischemic stroke in an academic center. Stroke 1999, 30:724-728.

125. Eisenstein EL, Shaw LK, Anstrom KJ, Nelson CL, Hakim Z, Hasselblad $\mathrm{V}$, Mark DB: Assessing the clinical and economic burden of coronary artery disease: 1986-1998. Med Care 200I, 39:824-835

126. Ghatnekar O, Persson U, Glader EL, Terent A: Cost of stroke in Sweden: an incidence estimate. Int J Technol Assess Health Care $2004,20: 375-380$. 
127. Salkeld G, Phongsavan P, Oldenburg B, Johannesson M, Convery P, Graham-Clarke P, Walker S, Shaw J: The cost-effectiveness of a cardiovascular risk reduction program in general practice. Health Policy 1997, 41: 105-I I9.

128. Samsa GP, Bian J, Lipscomb J, Matchar DB: Epidemiology of recurrent cerebral infarction: a medicare claims-based comparison of first and recurrent strokes on 2-year survival and cost. Stroke 1999, 30:338-349.

129. Sanders GD, Hlatky MA, Every NR, McDonald KM, Heidenreich PA Parsons LS, Owens DK: Potential cost-effectiveness of prophylactic use of the implantable cardioverter defibrillator or amiodarone after myocardial infarction. Ann Intern Med 200I, I 35:870-883.

130. Bronnum-Hansen H, Davidsen M, Thorvaldsen P: Long-term survival and causes of death after stroke. Stroke 200I, 32:2। $31-2136$

13I. Burn J, Dennis M, Bamford J, Sandercock P, Wade D, Warlow C: Long-term risk of recurrent stroke after a first-ever stroke. The Oxfordshire Community Stroke Project. Stroke 1994, 25:333-337.

132. Gage BF, Cardinalli AB, Owens DK: Cost-effectiveness of preference-based antithrombotic therapy for patients with nonvalvular atrial fibrillation. Stroke 1998, 29:|083-109|.

133. Hankey GJ, Jamrozik K, Broadhurst RJ, Forbes S, Burvill PW, Anderson CS, Stewart-Wynne EG: Five-year survival after first-ever stroke and related prognostic factors in the Perth Community Stroke Study. Stroke 2000, 3 I:2080-2086

134. Hardie K, Hankey G], Jamrozik K, Broadhurst RJ, Anderson C: Tenyear survival after first-ever stroke in the perth community stroke study. Stroke 2003, 34:1842-1846.

135. Hodgson C: Prevalence and disabilities of community-living seniors who report the effects of stroke. Can Med Assoc J 1998 , 159:S9-SI4.

136. Kiyohara Y, Kubo M, Kato I, Tanizaki Y, Tanaka K, Okubo K, Nakamura $\mathrm{H}$, lida $\mathrm{M}$ : Ten-year prognosis of stroke and risk factors for death in a Japanese community: the Hisayama study. Stroke 2003, 34:2343-2347.

137. Launbjerg J, Fruergaard P, Madsen JK, Mortensen LS, Hansen JF: Ten year mortality in patients with suspected acute myocardial infarction. BM] 1994, 308: I | 96- I I99.

138. Rosamond WD, Folsom AR, Chambless LE, Wang CH, McGovern PG, Howard G, Copper LS, Shahar E: Stroke incidence and survival among middle-aged adults: 9-year follow-up of the Atherosclerosis Risk in Communities (ARIC) cohort. Stroke 1999, 30:736-743

139. Simoons ML, Vos J, Martens LL: Cost-utility analysis of thrombolytic therapy. Eur Heart J 199I, I 2:694-699.

140. Tengs TO, Lin TH: A meta-analysis of quality-of-life estimates for stroke. Pharmacoeconomics 2003, 21:191-200.

141. Heart Disease and Stroke Statistics - 2005 update. American Heart Association 2005 [http://www.americanheart.org/down loadable/heart/I1053909/81 19HDSStats2005Update.pdf].

142. McGovern PG, Jacobs DR Jr., Shahar E, Arnett DK, Folsom AR, Black burn H, Luepker RV: Trends in acute coronary heart disease mortality, morbidity, and medical care from 1985 through 1997: the Minnesota heart survey. Circulation 200I, 104:19-24.

143. Williams GR, Jiang JG, Matchar DB, Samsa GP: Incidence and occurrence of total (first-ever and recurrent) stroke. Stroke $1999,30: 2523-2528$

144. Almela P, Benages A, Peiro S, Minguez M, Pena A, Pascual I, Mora F: Outpatient management of upper digestive hemorrhage not associated with portal hypertension: a large prospective cohort. Am J Gastroenterol 200I, 96:234I-2348.

145. Bjorkman DJ, Zaman A, Fennerty MB, Lieberman D, Disario JA, Guest-Warnick G: Urgent vs. elective endoscopy for acute non-variceal upper-GI bleeding: an effectiveness study. Gastrointest Endosc 2004, 60: I-8.

146. Cebollero-Santamaria F, Smith J, Gioe S, Van Frank T, Mc CR, Airhart J, Perrillo R: Selective outpatient management of upper gastrointestinal bleeding in the elderly. Am J Gastroenterol 1999 , 94: I242-1247.

147. Longstreth GF, Feitelberg SP: Outpatient care of selected patients with acute non-variceal upper gastrointestinal haemorrhage. Lancet 1995, 345:108-III.
148. Peura DA, Lanza FL, Gostout CJ, Foutch PG: The American College of Gastroenterology Bleeding Registry: preliminary findings. Am J Gastroenterol 1997, 92:924-928.

149. Podila PV, Ben Menachem T, Batra SK, Oruganti N, Posa P, Fogel R: Managing patients with acute, nonvariceal gastrointestinal hemorrhage: development and effectiveness of a clinical care pathway. Am / Gastroenterol 200I, 96:208-2I9.

150. Barkun A, Sabbah S, Enns R, Armstrong D, Gregor J, Fedorak RN, Rahme E, Toubouti Y, Martel M, Chiba N, Fallone CA: The Canadian Registry on Nonvariceal Upper Gastrointestinal Bleeding and Endoscopy (RUGBE): Endoscopic hemostasis and proton pump inhibition are associated with improved outcomes in a real-life setting. Am J Gastroenterol 2004, 99:1238-1246.

15I. Barkun AN, Cockeram AW, Plourde V, Fedorak RN: Review article: acid suppression in non-variceal acute upper gastrointestinal bleeding. Aliment Pharmacol Ther 1999, 13:1565-I584.

152. Branicki F], Coleman SY, Fok PJ, Pritchett C], Fan ST, Lai EC, Mok FP, Cheung WL, Lau PW, Tuen HH, .: Bleeding peptic ulcer: a prospective evaluation of risk factors for rebleeding and mortality. World J Surg 1990, 14:262-269.

153. Garripoli A, Mondardini A, Turco D, Martinoglio P, Secreto P, Ferrari A: Hospitalization for peptic ulcer bleeding: evaluation of a risk scoring system in clinical practice. Dig Liver Dis 2000, 32:577-582.

154. Katschinski B, Logan R, Davies J, Faulkner G, Pearson J, Langman M: Prognostic factors in upper gastrointestinal bleeding. Dig Dis Sci 1994, 39:706-712.

155. Klebl FH, Bregenzer N, Schofer L, Tamme W, Langgartner J, Scholmerich J, Messmann H: Comparison of inpatient and outpatient upper gastrointestinal haemorrhage. Int J Colorectal Dis 2005, 20:368-375

156. Lazzaroni M, Bianchi PG: Gastrointestinal side-effects of traditional non-steroidal anti-inflammatory drugs and new formulations. Aliment Pharmacol Ther 2004, 20 Suppl 2:48-58.

157. Masson J, Bramley PN, Herd K, McKnight GM, Park K, Brunt PW, McKinlay AW, Sinclair TS, Mowat NA: Upper gastrointestinal bleeding in an open-access dedicated unit. J $R$ Coll Physicians Lond 1996, 30:436-442.

158. Phang TS, Vornik V, Stubbs R: Risk assessment in upper gastrointestinal haemorrhage: implications for resource utilisation. N Z Med J 2000, I I 3:33 I-333.

159. Abt Associates Clinical Trials. SUCCESS-I costing review for the United States. 2004.

160. Spiegel BM, Vakil NB, Ofman J]: Dyspepsia management in primary care: a decision analysis of competing strategies. Gastroenterology 2002, 1 22: 1270-1285.

\section{Pre-publication history}

The pre-publication history for this paper can be accessed here:

http://www.biomedcentral.com/1471-230X/7/25/pre pub

Publish with Biomed Central and every scientist can read your work free of charge

"BioMed Central will be the most significant development for disseminating the results of biomedical research in our lifetime. "

Sir Paul Nurse, Cancer Research UK

Your research papers will be:

- available free of charge to the entire biomedical community

- peer reviewed and published immediately upon acceptance

- cited in PubMed and archived on PubMed Central

- yours - you keep the copyright 